Article

\title{
Adding Value to Waste Minerals in a Circular Economy Framework: Ochre-Derived Layered Double Hydroxide Catalysts in Fatty Acid Ketonisation
}

\author{
Diego D. Perera-Solis ${ }^{1,2}$, Matilda Pimlott ${ }^{2,3}$, Ella Fidment ${ }^{2,3}$, Andrew Whiting ${ }^{1,2}$ and \\ Hugh Christopher Greenwell 1,3,*(D) \\ 1 Centre for Sustainable Chemical Processes, Department of Chemistry, Durham University, Durham DH1 \\ 3LE, UK; diego.d.perera-solis@durham.ac.uk (D.D.P.-S.); andy.whiting@durham.ac.uk (A.W.) \\ 2 Department of Chemistry, Durham University, Durham DH1 3LE, UK; mapimlott@gmail.com (M.P.); \\ ellafidment@gmail.com (E.F.) \\ 3 Department of Earth Sciences, Durham University, Durham DH1 3LE, UK \\ * Correspondence: chris.greenwell@durham.ac.uk; Tel.: +44-191-334-2324
}

Received: 5 September 2019; Accepted: 1 November 2019; Published: 4 November 2019

\begin{abstract}
Transforming waste materials into added-value products is critical for a sustainable and circular economy. Here, $\mathrm{Mg} / \mathrm{Fe}$ layered double hydroxide (LDH) materials, with a $\mathrm{Mg}^{2+}: \mathrm{Fe}^{3+}$ ratio of 2 , were successfully synthesized via the co-precipitation method from a dissolved acid mine drainage precipitate waste "ochre", which is normally put to landfill. The prepared LDH materials were tested as a heterogeneous base catalyst to promote the production of the ketone, 12-tricosanone, from lauric acid, a component of plant oils, through a ketonic decarboxylation reaction, giving a circular economy route to catalysts for sustainable ketone production. The highest yield of the ketone observed was $80 \%$.
\end{abstract}

Keywords: ochre; ketonic decarboxylation; layered double hydroxide; waste; circular economy

\section{Introduction}

Treatment and reuse of waste is an important component of the emerging circular economy, where waste reduction and valorisation is needed to address the increasing population and the associated increasing consumer demand, which directly drives an increase in the consumption of goods, energy and the depletion of natural resources with associated increased waste to dispose of [1]. In particular, addressing climate change owing to emissions of greenhouse gases coming from industrial processes and fuel combustion is a major concern that requires immediate attention [1-3].

In recent years, significant research has been undertaken working towards routes to produce bio-derived synthons that otherwise would be produced by traditional petroleum-derived routes [4-6]. As an example, the base catalysed production of ketones from plant oil-derived fatty (and other carboxylic) acids has become an important reaction for the production of bio-based lubricants, fuel blends and detergents, as well as a mechanism to reduce the oxygen content within pyrolysis oil from biomass [3,7-9].

In our previous study [10], we explored and tested the heterogeneous base catalytic activity of layered double hydroxides (LDHs) to promote the formation of ketones from carboxylic acids through the ketonic decarboxylation reaction. Ketones are normally produced through oxidation of petroleum hydrocarbons, whereas ketonic decarboxylation is a deoxygenation reaction in which two carboxylic 
acids (for example, from tri-acylglycerides in plant oils) couple to form a ketone while releasing water and carbon dioxide [11,12]. A simple chemical equation to show ketonic decarboxylation is as follows:

$$
\mathrm{R}_{1} \mathrm{COOH}+\mathrm{R}_{2} \mathrm{COOH} \rightarrow \mathrm{R}_{1} \mathrm{COR}_{2}+\mathrm{CO}_{2}+\mathrm{H}_{2} \mathrm{O}
$$

Owing to their basic properties and structure $[10,13,14]$ (LDHs are materials composed of metal hydroxide brucite-like layers with interlayers that contain anions and water, charge balancing the compound), $\mathrm{Al} / \mathrm{Mg}$ synthetic LDHs proved to be excellent mediators of the ketonic decarboxylation reaction at moderate temperatures $\left(250^{\circ} \mathrm{C}\right)$ and offer a possible route for upgrading biomass-derived oils.

LDHs consist of hexa-platy, two-dimensional sheets of edge-sharing octahedra of metal cations (commonly $\mathrm{Mg}^{2+}$ and $\mathrm{Al}^{3+}$ ), with sheets stacked upon one another and with significant variation in cation composition possible during synthesis, allowing many actual and potential applications [13]. LDHs are generally prepared at scale using a co-precipitation method from soluble metal salts, and due to this, and attending the need for a circular economy, the use of an acid-soluble waste product sludge precipitated from acid mine drainage (AMD) treatment named ochre, which would typically be landfilled at a cost, could be an attractive cost-effective alternative source of cations to manufacture LDHs, which are used globally in industrial catalysis on a significant scale.

Ochre covers a group of ferric hydroxides, $\mathrm{FeO}(\mathrm{OH})$ or $\mathrm{Fe}(\mathrm{OH})_{3}$. According to Dobbie et al. [15], ochre production in the UK is estimated to be 30,000 tonnes per year at a disposal cost up to $£ 3$ million per year. Although only being used as pigments in fine art on a small-scale, the use of ochre as a potential phosphorus removal method has also been explored in recent years, with promising results, though no commercial application as yet [15-18]. However, to the best of our knowledge, ochre has not been used as yet as a cation source to synthesize $\mathrm{Mg} / \mathrm{Fe} \mathrm{LDHs}$.

In this paper, the use of the acid mine drainage precipitate ochre is investigated as a cation source material from which to synthesize LDHs, and the resulting material's activity as a heterogeneous base catalyst to promote the ketonic decarboxylation reaction between carboxylic acids is assessed. Hence, the overall aim being the transformation of an unwanted, waste material (ochre) into an added-value, useful, chemical material $(\mathrm{Mg} / \mathrm{Fe} \mathrm{LDH})$, with a range of potential sustainable chemical reaction applications, and herein exemplified by catalytic ketonic decarboxylation.

\section{Materials and Methods}

\subsection{Ochre Composition}

Ochre was obtained from the Coal Authority, UK, from the primary drying lagoon at Saltburn Gill Water Treatment Scheme, Saltburn, Cleveland, UK; a treatment system for an ironstone mine. Previous work has shown that the Saltburn ochre was mostly amorphous, with traces of goethite and 2-line ferrihydrite by XRD. Transmission electron microscopy showed that the majority of the material was nano-crystalline [19]. Dewatering analysis and inductively-coupled plasma-optical emission spectroscopy (ICP-OES) of the Saltburn ochre were performed to determine the composition. Dewatering was undertaken by placing an amount of ochre (approximately $5 \mathrm{~g}$ ) in an oven at $70{ }^{\circ} \mathrm{C}$ until constant mass was attained. Mineralogy was determined by powder X-ray diffraction, as detailed below.

\subsection{Catalyst Preparation}

The constant $\mathrm{pH}$ co-precipitation method (low saturation) was chosen to prepare the $\mathrm{Mg}-\mathrm{Fe}-\mathrm{CO}_{3}$ $\mathrm{LDH}\left(\mathrm{LDH}-\mathrm{CO}_{3}\right)$ with a target $\mathrm{Mg}$ :Fe ratio of $\sim 3.8$. This $\mathrm{Mg}$ :Fe ratio was selected on the basis of prior work, where co-precipitated $\mathrm{Mg} / \mathrm{Al} \mathrm{LDHs}$ showed the highest conversion for ketonic decarboxylation reactions [10]. Constant $\mathrm{pH}$ co-precipitation gives good control over nucleation rates, crystal morphology and composition homogeneity and allows for meaningful comparison with our previous study using Mg/Al LDH [10]. First, $5 \mathrm{~g}$ of Saltburn ochre (through ICP-OES analysis, in Table 1, the amount of iron in the $5 \mathrm{~g}$ Saltburn ochre is equivalent to $6.303 \mathrm{mmol}$ ) was dissolved in 
$50 \mathrm{~mL}$ of $3 \mathrm{M} \mathrm{HCl}$ (Fisher Scientific, Loughborough, United Kingdom, laboratory reagent grade) and mixed with $50 \mathrm{~mL}\left(24 \mathrm{mmol} \mathrm{Mg}\right.$ ) of a $0.48 \mathrm{M}$ solution of $\mathrm{Mg}\left(\mathrm{NO}_{3}\right)_{2} \cdot 6 \mathrm{H}_{2} \mathrm{O}$ (Sigma Aldrich, Gillingam, United Kingdom, 99\%). The mixed solution was added dropwise into a three-neck round bottom flask with $100 \mathrm{~mL}$ of $\mathrm{Na}_{2} \mathrm{CO}_{3}$ (Fisher, Scientific, Loughborough, United Kingdom, laboratory reagent grade) solution $(0.58 \mathrm{M})$, while stirred. To maintain the $\mathrm{pH}$ of the reaction at $10,100 \mathrm{~mL}$ of $\mathrm{NaOH}$ $1 \mathrm{M}$ was added dropwise, simultaneously. The temperature was controlled using a hot plate and an oil bath, keeping both the temperature and the stirring of the reactions always at $65^{\circ} \mathrm{C}$ and $300 \mathrm{rpm}$, respectively. Once the dissolved ochre solution addition was finished within the dropping funnel, the three-neck round bottom flask was sealed and put into an oven at $70{ }^{\circ} \mathrm{C}$ to age the product for $24 \mathrm{~h}$. Immediately after the aging process, the crude mixture was filtered using a Büchner funnel and filter paper to recover the precipitate. The solid product was washed with $1 \mathrm{~L}$ of deionized water and subsequently left in the oven at $70{ }^{\circ} \mathrm{C}$ for $24 \mathrm{~h}$ to dry. After drying, the solid material was ground and sieved using a $250 \mu \mathrm{m}$ sieve, leading to a fine brown powder. For a structural and catalytic comparison with the ochre-derived $\mathrm{LDH}$, another $\mathrm{LDH}$ using high purity metal salts was synthesized. A $0.04 \mathrm{M}$ solution ( $40 \mathrm{mmol}$ ) of $\mathrm{MgCl}_{2} \cdot 6 \mathrm{H}_{2} \mathrm{O}$ was mixed with a $0.02 \mathrm{M}$ solution $\left(20 \mathrm{mmol}\right.$ ) of $\mathrm{FeCl}_{3}$, which was added dropwise into $100 \mathrm{~mL}$ of $0.58 \mathrm{M}$ solution of $\mathrm{Na}_{2} \mathrm{CO}_{3}$ inside a three-neck round bottom flask using $\mathrm{NaOH}$ to regulate the $\mathrm{pH}$ at 10 . The rest of the methodology follows exactly as before.

\subsection{Catalyst Characterization}

\subsubsection{Powder X-Ray Diffraction (PXRD)}

The dried ochre and LDH powder samples were analysed using X-ray diffraction (XRD). A Brucker D8 Advanced XRD machine (Brucker, Berlin, Germany) was used with a Cu source, with radiation of $1.5418 \AA$ wavelength. The $2 \theta$ angle range was set to be $10-80^{\circ}$ and the sample was set to run for $45 \mathrm{~min}$ total scan time. The powder sample was mounted on a ground glass sample holder, and gently pressed to level prior to analysis.

\subsubsection{Thermogravimetric Analysis (TGA)}

TGA was performed using a Perkin Elmer Thermogravimetric Analyzer 8000 (Perkin Elmer, Seer Green, UK) under $\mathrm{N}_{2}$ gas flow $\left(30 \mathrm{~mL} \cdot \mathrm{min}^{-1}\right)$ to identify how much interlayer water was present in the samples. The temperature was varied from room temperature to $1000{ }^{\circ} \mathrm{C}$, increasing at $30{ }^{\circ} \mathrm{C}$ per minute.

\subsubsection{Fourier Transform Infrared (FTIR) Spectroscopy}

FTIR was performed using a Perkin Elmer FT-IR Spectrophotometer (Perkin Elmer, Seer Green, UK), using an attenuated total reflectance (ATR) cell to identify the functional groups and bonding in the samples. The analysis was performed in the wavenumber range from 400 to $4000 \mathrm{~cm}^{-1}$. Two scans were run per spectra. The force gauge was set at a consistent 105 units on the ATR cell anvil.

\subsubsection{Inductively-Coupled Plasma-Optical Emission Spectrometry (ICP-OES)}

The analysis was performed using a Jobin Yvon Horiba Ultima 2 ICP-OES (HORIBA Scientific, Piscataway, NJ, USA), fitted with a sequential monochromator and a radial torch (power $1050 \mathrm{~W}$ ) with cyclonic spray chamber and concentric nebulizer. For semi-quantitative analysis of most elements the instrument scans across the electromagnetic spectrum from 190 to $800 \mathrm{~nm}$. The emission lines recorded are then processed with the "Image" software which compares them with those in its library to identify and quantify the elements present in the sample.

\subsubsection{Brunauer-Emmett-Teller (BET) $\mathrm{N}_{2}$ Adsorption and Desorption Measurements}

Pore volume, surface area and average pore size were measured using a Micromeritics ASAP 2020 system (Version 3.00, Micromeritics, Hexton, UK) at $-196^{\circ} \mathrm{C}$, with samples degassed at $80^{\circ} \mathrm{C}$. 


\subsection{Ketonic Decarboxylation Reaction Procedure}

A total of $0.4004 \mathrm{~g}, 2 \mathrm{mmol}$ of dodecanoic acid $\left(\mathrm{C}_{12} \mathrm{H}_{24} \mathrm{O}_{2}, \mathrm{TCI}, 98 \%\right)$ was reacted at temperatures ranging from 250 to $350{ }^{\circ} \mathrm{C}$ with different catalyst loadings $(5 \%, 3 \%$ and $1 \%$ with respect to the feed of dodecanoic acid, in grams) inside an autoclave (0.075 L Parr), using toluene as solvent (analytical grade, Fisher) to convert the dodecanoic acid into the homo-ketonisation product, 12-tricosanone. Once sealed, the autoclave was purged with nitrogen four times to remove any trace of oxygen within the vessel. Afterwards, the autoclave was heated up to the desired temperature and left to react for one hour. Once the reaction time was over, the vessel was left to cool down and, once at room temperature, the crude product was taken out of the reactor using a $20 \mathrm{~mL}$ pipette.

Analysis of Crude Reaction Product

The crude product was put into a $50 \mathrm{~mL}$ falcon tube and centrifuged using a Beckman Coulter Avanti J-20XP centrifuge (Beckman Coulter, Wycombe, UK) (3000 RPM, 15 min) to separate the solid catalyst. The crude product was analysed using a Shimadzu GC-2010 instrument (Shimadzu, Wolverton, UK) with a flame ionization detector (FID) with a HP-5 $30 \mathrm{~m}$ length, $0.25 \mathrm{~mm}$ internal diameter and $0.25 \mu \mathrm{m}$ film thickness coating column (stationary phase: 5\% diphenyl/95\% dimethylpolysiloxane), using hydrogen $\left(\mathrm{H}_{2}\right)$ as the carrier gas. Before injection, a calibration curve using the internal standard method for the amount of the expected ketone was performed in order to perform the quantitative analysis (see Figure S1).

\section{Results}

\subsection{Saltburn Ochre and As-Synthesized $\mathrm{LDH}_{-} \mathrm{CO}_{3}$ (Ochre-Derived and Synthetic) Characterization}

The results from the ICP-OES analysis of the Saltburn ochre and the as-synthesized $\mathrm{LDH}-\mathrm{CO}_{3}$ (ochre-derived and synthetic) are shown in Table 1. To avoid confusion, the ochre-derived LDH will be called $\mathrm{LDH}-\mathrm{CO}_{3}$ whereas the synthetic $\mathrm{LDH}$ will be termed $\mathrm{SLDH}-\mathrm{CO}_{3}$. The presence of different metals in the Saltburn ochre can be observed, with Fe being the most abundant by an order of magnitude, followed by Ca. The average amount of water in Saltburn ochre corresponds to 78.2\% (See Table S1).

For the $\mathrm{LDH}-\mathrm{CO}_{3}$, the analysis suggests that the synthesized material contains an Mg:Fe ratio of 3 rather than the calculated $\sim 3.8$. This reflects variability of the composition of the Saltburn ochre, and an assumption of the ochre being composed mainly of $\mathrm{FeO}(\mathrm{OH})$ in the calculated composition. The low-saturation method for co-precipitation was used for the synthesis of the LDH materials as it produces more crystalline precipitates when compared with the high saturation method, as well as being more commonly used for the synthesis of LDH materials [20].

Based on the obtained Mg:Fe ratio of 3 and following the literature [13,14], the estimated formula, $\left[\mathrm{Mg}_{0.75}^{2+} \mathrm{Fe}_{0.25}^{3+}\left(\mathrm{OH}_{2}\right)\right]^{0.25+}\left(\mathrm{CO}_{3}^{2-}\right)_{0.125} \cdot \mathrm{mH}_{2} \mathrm{O}$, for the $\mathrm{LDH}-\mathrm{CO}_{3}$ was calculated. In the same manner, and according to Table 1, the Mg:Fe ratio of $\mathrm{SLDH}_{-} \mathrm{CO}_{3}$ was calculated and a value of 2.11 was obtained, which is in agreement with the desired ratio based on the reactant stoichiometry. The chemical formula of SLDH- $\mathrm{CO}_{3}$ was calculated as $\left[\mathrm{Mg}_{0.68}^{2+} \mathrm{Fe}_{0.32}^{3+}\left(\mathrm{OH}_{2}\right)\right]^{0.32+}\left(\mathrm{CO}_{3}^{2-}\right)_{0.16} \cdot \mathrm{mH}_{2} \mathrm{O}$.

TGA analysis of the Saltburn ochre was performed to observe if any organic matter was present within the sample. The plot is shown in Figure 1, together with the one belonging to the $\mathrm{LDH}_{-} \mathrm{CO}_{3}$, and it can be observed that the materials have very different mass loss profiles. The ochre sample loses mass in two main steps, one in the region of the $200{ }^{\circ} \mathrm{C}$ and the next one in between 200 and $650{ }^{\circ} \mathrm{C}$. The first mass loss is due to the removal of physiosorbed water on the sample, whereas the second one relates to the dehydroxylation of the sample, as all the $\alpha-\mathrm{FeO}(\mathrm{OH})($ goethite) was completely transformed to $\alpha-\mathrm{Fe}_{2} \mathrm{O}_{3}$ (hematite) [21-23], with the latter confirmed by XRD data of a calcined Saltburn ochre sample at $800{ }^{\circ} \mathrm{C}$ (see Figure S2). 
Table 1. Concentration of metals present in the Saltburn ochre, the ochre-derived LDH (i.e., $\mathrm{LDH}-\mathrm{CO}_{3}$ ) and the synthetic $\mathrm{LDH}$ (i.e., $\mathrm{SLDH}-\mathrm{CO}_{3}$ ) samples dissolved in $\mathrm{HCl}(\mathrm{ppm})$, from ICP analysis.

\begin{tabular}{|c|c|c|c|c|c|c|}
\hline Element & $\begin{array}{l}\text { Concentration (ppm) in } \\
5 \mathrm{~g} \text { of Saltburn Ochre }\end{array}$ & SD * & $\begin{array}{l}\text { Concentration (ppm) } \\
\text { in } 15 \mathrm{mg} \text { of } \mathrm{LDH}-\mathrm{CO}_{3}\end{array}$ & SD * & $\begin{array}{c}\text { Concentration (ppm) } \\
\text { in } 15 \mathrm{mg} \text { of SLDH-CO }{ }_{3}\end{array}$ & SD * \\
\hline $\mathrm{Mg}$ & 32.4 & 1.4 & 270 & 37.8 & 190 & 30.5 \\
\hline $\mathrm{Fe}$ & 6091 & 17.6 & 210 & 15.2 & 210 & 20.8 \\
\hline $\mathrm{Ca}$ & 499.1 & 1.5 & 15 & 2.1 & 0.52 & 0.01 \\
\hline $\mathrm{Si}$ & 12 & 0.12 & 8 & 2.8 & 6.6 & 2.8 \\
\hline $\mathrm{Ba}$ & 0.4 & 0.1 & 0.94 & 0.5 & 0.94 & 0.5 \\
\hline $\mathrm{Tb}$ & 1 & 0.012 & 0.77 & 2.3 & 0.31 & 2.3 \\
\hline $\mathrm{K}$ & 0.09 & 0.1 & 0.72 & 0.6 & 0.56 & 0.6 \\
\hline $\mathrm{Mn}$ & 6.3 & 0.1 & 0.62 & 0.1 & 1.1 & 0.1 \\
\hline $\mathrm{Na}$ & 2 & 0.1 & 0.57 & 0.1 & 4.1 & 0.1 \\
\hline $\mathrm{Sr}$ & 10.8 & 0.1 & 0.55 & 0.04 & - & - \\
\hline
\end{tabular}

* The rest of the minor metal constituents are shown in the Table S2. SD means standard deviation, of concentration measured in triplicate.

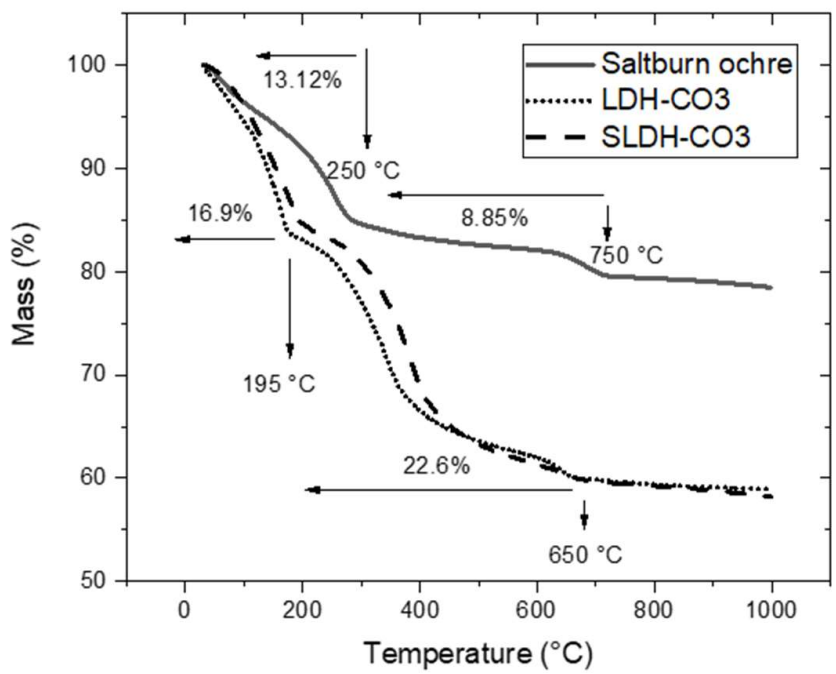

Figure 1. Thermogravimetric analysis of the Saltburn ochre and the as-synthesized ochre derived $\mathrm{LDH}-\mathrm{CO}_{3}$ and metal salt derived $\mathrm{SLDH}-\mathrm{CO}_{3}$ samples under a $\mathrm{N}_{2}$ atmosphere.

TGA analysis of the $\mathrm{LDH}-\mathrm{CO}_{3}$ exhibits a typical three-stage decomposition, [24] with a total mass loss of $39.5 \%$ as the temperature reached $650{ }^{\circ} \mathrm{C}$. These mass losses are due to the water adsorbed (up to $\mathrm{ca} 120^{\circ} \mathrm{C}$ ) and in the interlayer (up to $250^{\circ} \mathrm{C}$ ) being removed, followed by dehydroxylation and loss of the interlayer carbonate species, resulting in spinel formation at above $750{ }^{\circ} \mathrm{C}[20,24-26]$. $\mathrm{SLDH}-\mathrm{CO}_{3}$ exhibited the same behaviour as $\mathrm{LDH}-\mathrm{CO}_{3}$, as observed in Figure 1. Thus, the two larger mass losses can be attributed to dehydroxylation and decomposition of the carbonate species existing in the interlayer.

The mineralogy of the Saltburn ochre was analysed using powder XRD, as shown in Figure 2a. The main reflections present in the sample are from goethite $(\alpha-\mathrm{FeO}(\mathrm{OH}))$, which is generally the main iron phase observed in ochre [17]. The broad background feature arises owing to fluorescence effects associated with Fe phases. When compared to the powder XRD pattern of the ochre, it is clear a new phase has been formed in LDH synthesis (Figure 3). 

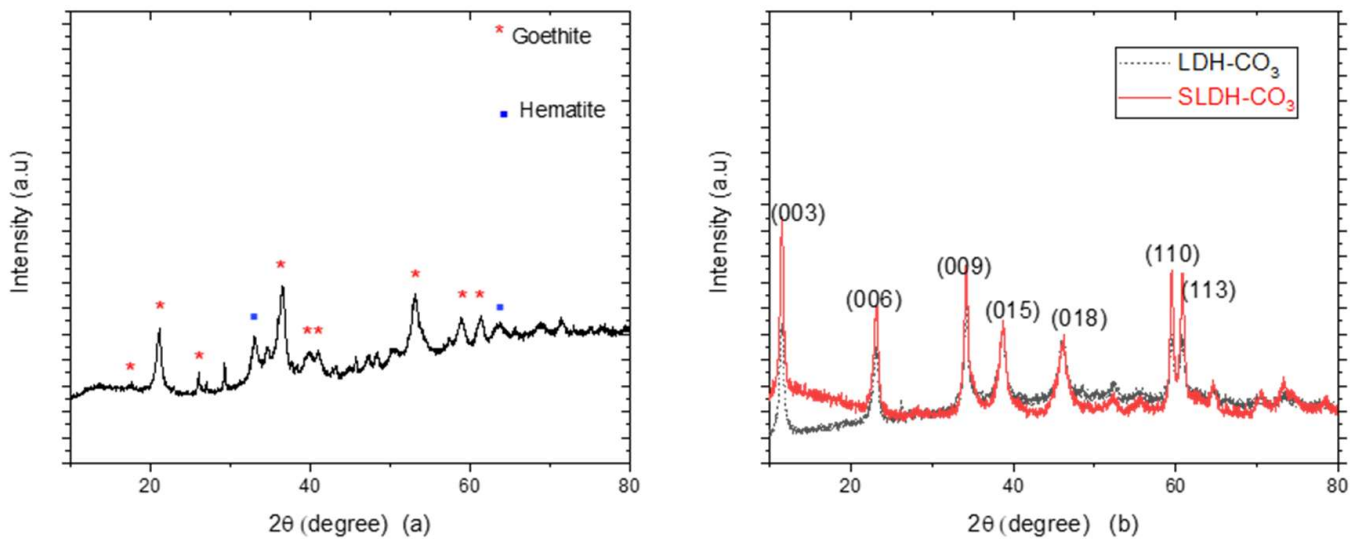

Figure 2. (a) Powder X-ray diffraction pattern of the Saltburn ochre. Characteristic reflection peaks from goethite can be observed as denoted by *; (b) powder X-ray diffraction pattern of the synthesized ochre derived $\mathrm{LDH}-\mathrm{CO} 3$ and metal salt derived $\mathrm{SLDH}-\mathrm{CO}_{3}$ with characteristic diffraction peaks for layered double-hydroxide (LDH) structures.

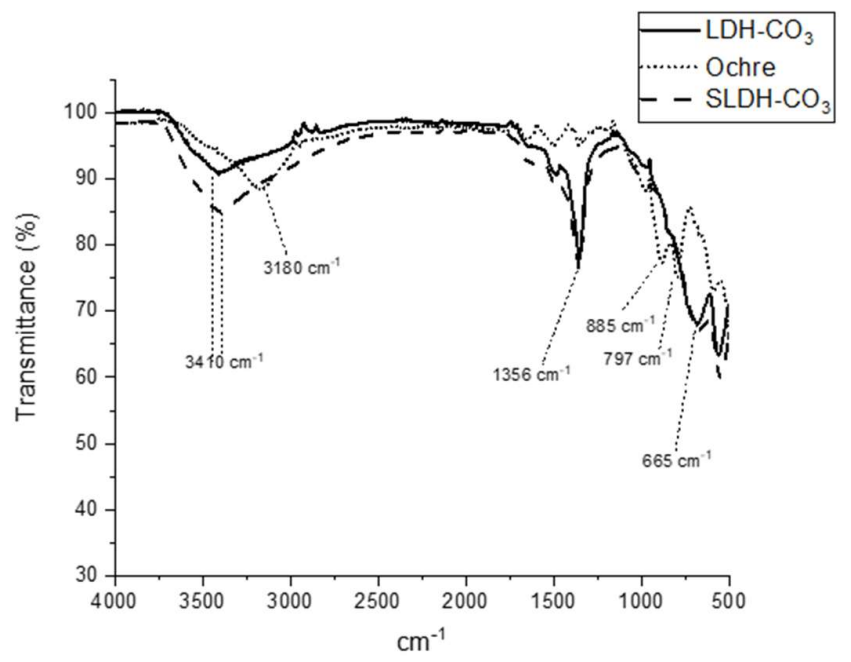

Figure 3. Fourier transform infrared spectra of both layered double hydroxide (LDH) samples $\left(\mathrm{LDH}-\mathrm{CO}_{3}=\right.$ ochre derived $\mathrm{LDH} ; \mathrm{SLDH}-\mathrm{CO}_{3}=$ metal salt derived $\left.\mathrm{LDH}\right)$ and Saltburn ochre. O-H stretching from 3000 to $3500 \mathrm{~cm}^{-1}$. Stretching of the $\mathrm{C}=\mathrm{O}$ bonds at $1356 \mathrm{~cm}^{-1}$.

The sharp reflections from the XRD pattern observed in Figure $2 \mathrm{~b}$ correspond to those characteristic of LDHs, showing that the as-synthesized material by the co-precipitation method is a well-crystallized $\mathrm{LDH}[10,27-29]$. The basal $d$-spacing and interlayer repeat distance from the sample $\mathrm{LDH}-\mathrm{CO}_{3}$ is 7.683 $\AA$, typical for carbonate containing LDHs [20]. The crystal cell $a$ parameter was calculated as $3.103 \AA$ (using $a=2 d_{(110)}$ ), and the crystal cell $c$ parameter (calculated as $c=3 d_{(003)}$ ) was $23.1 \AA$, in accord with the literature [24,30-32]. The broad background feature may be due to fluorescence, or possibly the presence of an amorphous Fe oxide phase. Using the same methodology, crystal cell parameters were calculated for SLDH-CO $\mathrm{CO}_{3}$. The values of the $d$-spacing and interlayer repeat distance, as well as the values of $a$ and $c$, were 7.73, 31.01 and $23.19 \AA$, respectively.

The FTIR spectra from the Saltburn ochre and the $\mathrm{LDH}-\mathrm{CO}_{3}$ and $\mathrm{SLDH}-\mathrm{CO}_{3}$ samples are presented in Figure 3. Principle adsorptions corresponding to the LDH are a broad adsorption band from 3000 to $3500 \mathrm{~cm}^{-1}$, with an observable peak at $3410 \mathrm{~cm}^{-1}$, corresponding to hydrogen-bonded -OH and interlayer water $[20,31]$, and a distinctive intense absorption at $1356 \mathrm{~cm}^{-1}$ corresponding to carbonate anti-symmetric stretching, as well as an observable shoulder close to $2900 \mathrm{~cm}^{-1}$ related to stretching bonding of $\mathrm{H}$-bonded molecules $\left(\mathrm{O}-\mathrm{H}\right.$ bonded to the $\mathrm{CO}_{3}^{2-}$ in the interlayer $)[26,29,33,34]$. Regarding the Saltburn ochre sample, the peaks observed at 797 and $885 \mathrm{~cm}^{-1}$ can be attributed to those 
characteristic of goethite, due to the deformation of the $\mathrm{O}-\mathrm{H}$ bonds [35-37], supporting the data obtained from the XRD. Taken together, XRD, TGA and FTIR analysis all confirm that the original ochre is comprised mainly of goethite and the material has been substantially, if not completely, re-precipitated as an $\mathrm{LDH}$ material.

The plots from the nitrogen adsorption and desorption isotherms, for calculation of the specific surface area as well as the pore size distribution curve, are presented in Figure 4, for the BET (a) and the Barrett-Joyner-Halenda (BHJ) (b and c) methods, for both catalysts.
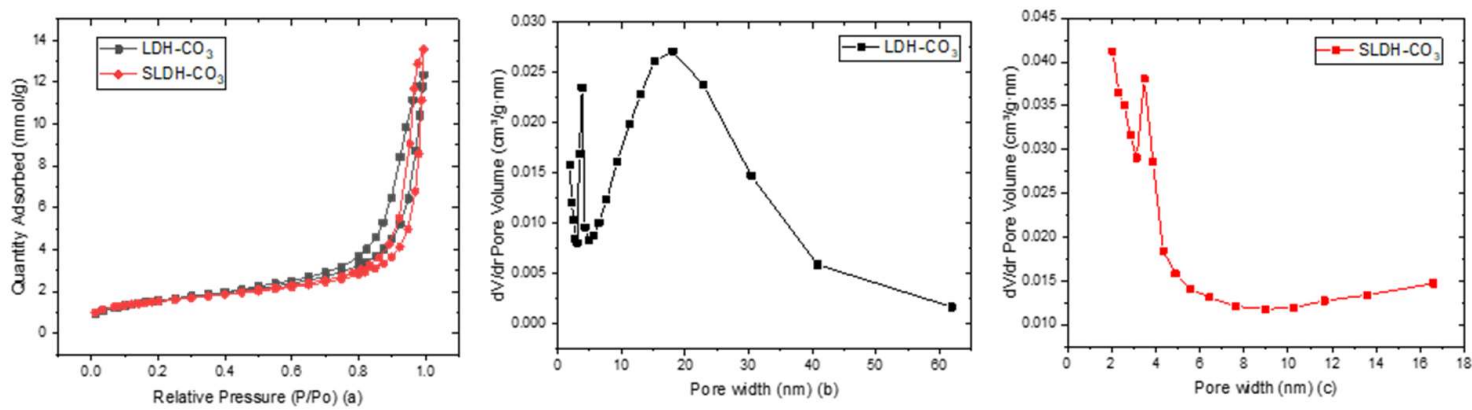

Figure 4. Nitrogen adsorption/desorption isotherms of the ochre derived $\mathrm{LDH}-\mathrm{CO}_{3}$ and metal salt $\mathrm{SLDH}-\mathrm{CO}_{3}(\mathbf{a})$. Pore size distribution curves of the $\mathrm{LDH}-\mathrm{CO}_{3}(\mathbf{b})$ and $\mathrm{SLDH}-\mathrm{CO}_{3}$ (c). Regarding the Barrett-Joyner-Halenda (BHJ) method, both samples were separated in two different plots.

The materials exhibited a classical Type IV isotherm related with mesoporous materials [38,39] with a narrow hysteresis loop, which means that the pores are uniformly distributed in a narrow arrangement $[38,39]$. This distribution was confirmed by Figure $4 \mathrm{~b}$ for the $\mathrm{LDH}-\mathrm{CO}_{3}$, in which it can be observed that the majority of the pores are distributed between a width of 9 and $40 \mathrm{~nm}$. On the other hand, the majority of the mesopores for the $\mathrm{SLDH}-\mathrm{CO}_{3}$ were up to $20 \mathrm{~nm}$ in width. A summary of the specific surface, pore volume as well as pore size for both samples can be observed in Table 2.

Table 2. Obtained results from specific surface area and pore parameters from the Brunauer-Emmett-Teller (BET) and the Barrett-Joyner-Halenda (BHJ) for the ochre-based LDH $\left(\mathrm{LDH}-\mathrm{CO}_{3}\right)$ as well as the synthetic one $\left(\mathrm{SLDH}-\mathrm{CO}_{3}\right)$.

\begin{tabular}{ccc}
\hline Parameter of the Material & LDH-CO & SLDH-CO $_{3}$ \\
\hline Specific surface area $\left(\mathrm{m}^{2} \cdot \mathrm{g}^{-1}\right)$ & 125.91 & 20.92 \\
Pore volume $\left(\mathrm{cm}^{3} / \mathrm{g}\right)$ & 0.39 & 0.13 \\
Pore width $(\mathrm{nm})$ & 14.90 & 2.90 \\
\hline
\end{tabular}

According to the reported data in Table 2, the BET surface area as well as the pore size parameters seem to be in agreement with the literature $[10,40]$.

\section{2. $\mathrm{LDH}_{-} \mathrm{CO}_{3}$ as a Catalyst for the Ketonic Decarboxylation of Lauric Acid}

Ketonic decarboxylation reactions were carried out using the ochre-derived $\mathrm{Mg} / \mathrm{Fe} \mathrm{LDH}-\mathrm{CO}_{3}$ as a heterogeneous base catalyst, with lauric acid (dodecanoic acid) as the substrate at two different temperatures $\left(250\right.$ and $\left.300{ }^{\circ} \mathrm{C}\right)$ and with different catalyst loads ranging from $1 \%$ to $5 \%$ with respect to the feed in grams, as shown in Section 2.2. The results are presented in Figure 5. Conversion was considered to be $100 \%$ as well as selectivity towards the ketone, as no other significant peaks were observed in the chromatograms of the crude product mixture (Figure S3), and were as performed in our previous study [10]. To screen the potential use of Saltburn ochre as a heterogeneous catalyst and the capability of the waste material to promote the formation of ketones compared with the synthetic $\mathrm{LDH}-\mathrm{CO}_{3}, 5 \%$ of the Saltburn ochre was tested under the same conditions as those detailed 
in Section 2.4 for a reaction temperature of $300{ }^{\circ} \mathrm{C}$. The ketone yield was $16 \%$, much lower (relatively) than that obtained with the as-synthetized $\mathrm{LDH}_{-} \mathrm{CO}_{3}$.

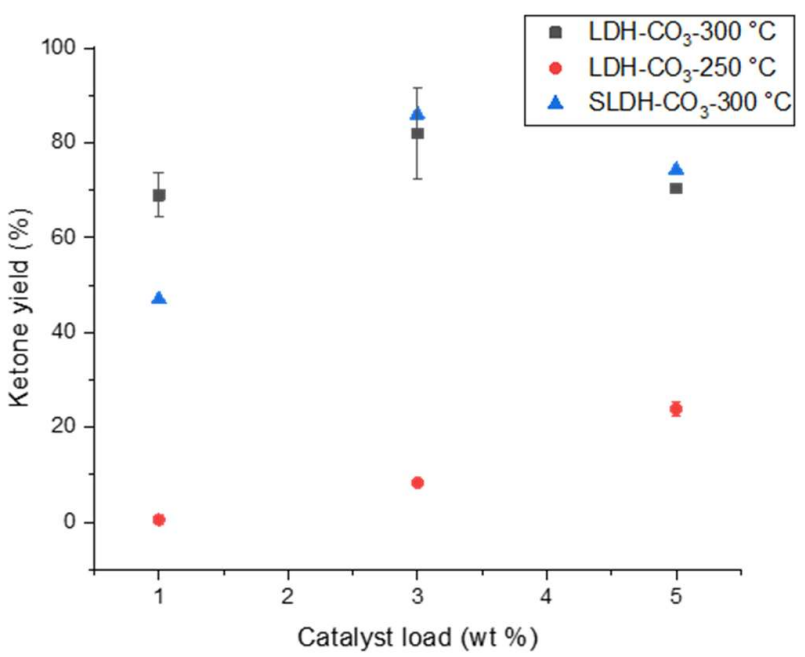

Figure 5. Yield of 12-tricosanone derived from the ketonic decarboxylation of lauric acid with the $\mathrm{LDH}-\mathrm{CO}_{3}$ and $\mathrm{SLDH}-\mathrm{CO}_{3}$.

Moreover, the $\mathrm{SLDH}-\mathrm{CO}_{3}$ catalyst was also screened in order to compare the activity of this material, made with high purity reagents, with the activity showed by the $\mathrm{LDH}-\mathrm{CO}_{3}$, which was synthesized with the waste material ochre. The screening of the catalyst of this catalyst was performed once under the same conditions presented in Section 2.4 at a reaction temperature of $300{ }^{\circ} \mathrm{C}$ (Table S3), as observed in Figure 5. Some literature reports state that for ketonic decarboxylation to occur, temperatures of above $320^{\circ} \mathrm{C}$ are required [7,9]. In addition to this, in our previous study, ketonic decarboxylation was achieved at $250^{\circ} \mathrm{C}$ [10]. When temperatures higher than $300^{\circ} \mathrm{C}$ were screened for this present study, pyrolytic decomposition of the lauric acid occurred, forming a number of aromatic products, as a result of the solvent (toluene) also behaving as a reactant. In addition, a control was performed where lauric acid was screened without solvent and catalyst to temperatures at $300{ }^{\circ} \mathrm{C}$ and above, which resulted in decomposition of the reactant into volatiles and with no trace of ketone in the remaining crude product in the reaction vessel. Thus, taking into account the results when screening temperatures over $300{ }^{\circ} \mathrm{C}$ for these experiments and the results from our previous study, the temperature was set to two values (i.e., 250 and $300^{\circ} \mathrm{C}$ ) for evaluation of the ketonisation reaction.

For the evaluation of the $\mathrm{LDH}-\mathrm{CO}_{3}$, each reaction was carried out in triplicate, and, as observed in Figure 5, error bars show the standard deviation existing for each catalyst load percentage at both temperatures. However, regarding the $250{ }^{\circ} \mathrm{C}$ points, the deviation was so small that they can barely be discerned relative to the size of the data point markers.

It can be observed from the data above (Figure 5) that the ketonic decarboxylation of lauric acid using the $\mathrm{SLDH}-\mathrm{CO}_{3}$ exhibited a higher conversion of the latter into the desired ketone; however, the difference in ketone yield between the two catalysts was slight. Nevertheless, an appreciable difference was observed at $1 \%$ catalyst loading, where the $\mathrm{LDH}-\mathrm{CO}_{3}$ (i.e., the one made using the Saltburn ochre) delivered a better result than the synthetic one.

\section{Discussion}

Here, we valorise a waste product, ochre, from the Saltburn Gill treatment scheme, that would have otherwise been landfilled, through converting it to a $\mathrm{Mg} / \mathrm{Fe} \mathrm{LDH}-\mathrm{CO}_{3}$ solid base catalyst material. Though we use here a purchased $\mathrm{Mg}$ salt, waste streams containing dissolved $\mathrm{Mg}$ may be identified in order to accrue further environmental and sustainability benefits. 


\subsection{Characterisation of Ochre to LDH Conversion}

Analysis of the ochre showed the sample was mainly goethite (ICP and XRD) with some Si, Ca compounds and water, with no observable presence of any organic matter, agreeing with the literature [17]. Despite other metals being found within the ochre sample, as identified by ICP-OES in Table 1, the high level of Fe made it a suitable donor waste material for the synthesis of the $\mathrm{Mg} / \mathrm{Fe}$ LDH. The formed LDH structures have a very different XRD pattern to the ochre (Figure 2a,b), are low-order, polycrystalline materials and have characteristic sharp, intense basal reflections, with preferred orientation low $2 \theta$ angles and with almost equally intense, symmetric reflections at high $2 \theta$ angles, as seen in Figure $2 b[10,27,28]$. The obtained lattice parameters $a$ and $c$, which represents the cation-cation distance in the layer and three times the distance in adjacent brucite-like layers, respectively, fits very well with the reported data for synthetic layered double hydroxides and natural hydrotalcites in the literature, with $a$ and $c$ values of 3.06 and $23 \AA$, respectively, reported by Brito et al. [25]. Cavani et al. [20] reported values from 3.05 to $3.11 \AA$ for $a$, whereas for $c$, values from 22.81 to $23.41 \AA$ were reported. Other similar values of $a$ and c, 3.04 and $23.64 \AA$, respectively, were also reported by Cocheti et al. [41]. The symmetrical nature of the $01 \mathrm{l}$ reflections is interesting, indicating low turbostratic disorder within the prepared $\mathrm{Mg} / \mathrm{Fe} \mathrm{LDH}$.

The FTIR data provided further information about the LDH materials, with hydrogen-bonded $\mathrm{O}-\mathrm{H}$ group stretching evident in the region 3000 to $3500 \mathrm{~cm}^{-1}[26,33]$, related to the existence of water in the interlayer, with no similar high wavenumber vibrations in the ochre spectra, where interlayer regions are not present. The presence of a peak at $1356 \mathrm{~cm}^{-1}$ related to the carbonate anion is due to the anti-symmetric stretching of the C-O bond [20,29]. The data is characteristic of LDHs [42,43], supporting the XRD data above regarding a successful synthesis of the desired LDH material. The latter can also be supported with the FTIR plot of the Saltburn ochre observed in Figure 3, with the characteristic goethite peaks at 797 and $885 \mathrm{~cm}^{-1}$ [35-37] and their total disappearance in the LDH spectra. No sharp absorbance was observed circa $3700 \mathrm{~cm}^{-1}$, which would also indicate the presence of a brucite $\left(\mathrm{Mg}(\mathrm{OH})_{2}\right)$ phase.

The nitrogen adsorption and desorption isotherms proved the mesoporous nature of the as-synthesized $\mathrm{LDH}$ material $\left(\mathrm{LDH}-\mathrm{CO}_{3}\right)$, with a narrow distribution of pore size and a relatively high surface area, both desirable characteristics for heterogeneous catalysts, with good adsorption properties favouring the diffusion of products and reactants [44]. When compared with the latter, the BET surface area calculated for the $\mathrm{SLDH}-\mathrm{CO}_{3}$ is smaller (see Table 2); however, when evaluated for carrying out the ketonic decarboxylation reaction at $300{ }^{\circ} \mathrm{C}$, the yield of ketone produced was similar to the material with a higher surface area (see Table S3), showing that the existing difference between both samples in terms of area might not be significant enough to effect product yield.

The target ratio (R-value) of $\mathrm{Mg}^{2+}: \mathrm{Fe}^{3+}$ for this study was 3.8; however, and according to the ICP-OES analysis of the $\mathrm{LDH}-\mathrm{CO}_{3}$ sample, a ratio of $\mathrm{Mg}^{2+}: \mathrm{Fe}^{3+}$ of 3 was obtained. The amount of $\mathrm{Mg}$ present in the $\mathrm{LDH}-\mathrm{CO}_{3}$ was less than expected according to the stoichiometry of the reactants used for the synthesis of the material. We speculate that this was due to the presence of amorphous $\mathrm{Mg} / \mathrm{Fe}$ oxides in the sample, as no other appreciable phases related to $\mathrm{Mg}$ (for example, $\mathrm{Mg}(\mathrm{OH})_{2}$ or $\mathrm{MgO}$ ) or Fe (for example, $\mathrm{FeO}(\mathrm{OH})$ are observed either in the PXRD pattern or the FTIR spectra [45]. On the other hand, a Mg:Fe ratio of 2.11 was obtained for the $\mathrm{SLDH}-\mathrm{CO}_{3}$, as expected when synthesized, with the desired synthesis R-value set at 2. The use of ochre; therefore, may present a challenge in terms of obtaining well-defined $\mathrm{Mg}$ :Fe ratios.

It should be noted that the stoichiometry for the $\mathrm{Mg}^{2+}: \mathrm{Fe}^{3+}$ ratio for the $\mathrm{LDH}-\mathrm{CO}_{3}$ was based on the amount of iron present in the Saltburn ochre, which was first measured using ICP-OES on the latter and allowing for the dewatering analysis described in Section 3.1. The element composition given in Table 1 is an average of the concentration of metals in the Saltburn ochre for several samples, with distribution being slightly heterogeneous owing to the nature of the waste material. The amount of $\mathrm{M}^{3+}$ substitution present in the layer, in this case, the $\mathrm{Fe}^{3+}$ cation, can vary depending on the methodology used for the synthesis as well as the conditions of the latter. A ratio of $\mathrm{M}^{2+}: \mathrm{M}^{3+}$ varying from 2 to 6 has 
been observed in synthetic LDHs in the literature, with natural minerals mainly presenting a ratio of 2 or $3[30]$.

The TGA plot in Figure 1 delivers a clear comparison between the as-synthesized $\mathrm{LDH}-\mathrm{CO}_{3}$, $\mathrm{SLDH}-\mathrm{CO}_{3}$ and the Saltburn ochre. It can be observed that, as expected and in agreement with the XRD and FTIR data, the ochre was transformed completely into the LDH material and the decomposition curve changed considerably as a result.

Ochre is mainly composed of goethite, as observed in Figure 2a, and all the mass loss observed in Figure 1 is due to the loss of adsorbed water and the dehydroxylation of the sample, with the goethite completely transformed into hematite when temperatures reached $700{ }^{\circ} \mathrm{C}$ and above $[17,21,23]$. When observing the TGA curve for both the $\mathrm{LDH}-\mathrm{CO}_{3}$ and $\mathrm{SLDH}-\mathrm{CO}_{3}$, literature report a classical two stages decomposition in hydrotalcite-like materials, with the first mass loss due to the physiosorbed and interlayer water, which ends at around $200{ }^{\circ} \mathrm{C}$, and a second mass loss from $200{ }^{\circ} \mathrm{C}$ to approximately 600 ${ }^{\circ} \mathrm{C}$ due to the dehydroxylation and decomposition of the carbonate anion in the interlayer [20,24-26]. Both processes can be considered endothermic and dependent on different factors, such as the cation ratio, pre-treatment of the samples and type of anions in the interlayer [20].

\subsection{Ketonic Decarboxylation of Lauric Acid}

The catalyst load and the temperature at which each reaction was performed have a direct impact on the formation of ketone. Thus, when no catalyst was used, ketone production did not occur. However, in the presence of catalytic amounts of the LDH materials, the ketone started to be generated, in lower yields at lower temperatures $\left(250^{\circ} \mathrm{C}\right)$ and in much higher yields when the temperature increased $\left(300^{\circ} \mathrm{C}\right)$, as shown in Figure 5. It should be noted that the raw Saltburn ochre did promote the ketonic decarboxylation of lauric acid; however, the ketone yield was low $\left(16 \%\right.$ at $\left.300{ }^{\circ} \mathrm{C}\right)$ when compared with those obtained with the $\mathrm{Mg} / \mathrm{Fe} \mathrm{LDH}-\mathrm{CO}_{3}$.

Even though the ketone yield was low, the Saltburn ochre, which is mainly composed of goethite (see Figure 2a), did show some activity as a basic heterogeneous catalyst. The catalytic behaviour of $\mathrm{FeO}(\mathrm{OH})$ has previously been observed for reforming or cracking of heavy oils [46,47]; however, no reaction mechanism was described. According to recent literature, this catalytic behaviour could be attributed to the presence of the existing $\mathrm{O}-\mathrm{H}$ groups and the adsorbed carboxylic acids reacting through formation of a $\beta$-keto acid intermediate $[10,12,48]$.

The need for a mineral surface to drive catalysis fits with the experimental data from other authors, indicating the surface plays a major role to promote the ketonic decarboxylation reaction, based on the organization of the reactants over the surface of the catalyst and the involvement of specific active sites $[10,49,50]$. When no basic catalyst is present, the abstraction of the $\alpha$-hydrogen does not occur, which prevents the ketone forming [11]. In our previous study [10], up to $90 \%$ ketone yield was observed when $\mathrm{Mg} / \mathrm{Al} \mathrm{LDHs}$ were used at $250{ }^{\circ} \mathrm{C}$ for conversion of stearic acid, whereas in this study using the ochre-derived $\mathrm{LDH}\left(\mathrm{LDH}-\mathrm{CO}_{3}\right)$ with lauric acid, the highest ketone yield obtained at that temperature was 19\% (see Figure 5). Higher conversion (of up to $80 \%$ ) is attained with the $\mathrm{LDH}-\mathrm{CO}_{3}$ catalysts here at $300{ }^{\circ} \mathrm{C}$. The effect of reaction time, substrate differences (lauric vs stearic acid) and catalyst composition ( $\mathrm{Mg} / \mathrm{Al}$ vs. $\mathrm{Mg} / \mathrm{Fe})$ is presently being investigated to understand these differences.

The effectiveness of $\mathrm{SLDH}-\mathrm{CO}_{3}$ as a heterogeneous base catalyst to promote ketonic decarboxylation can be observed in Table 2. Higher ketone yields were obtained when compared with the ochre-derived $\mathrm{LDH}-\mathrm{CO}_{3}$ and it might be assumed that this is due to the purity of the reactants. However, the ketone yield obtained from the Saltburn ochre-derived material with a catalyst loading of $3 \%$ was close to the yield obtained with the high purity reactants, proving that ochre can be an efficient iron donor to produce highly active LDH materials, with impurities having negligible effect. Despite the different $\mathrm{Mg}$ :Fe ratios for both materials, the SLDH-CO ${ }_{3}$ and $\mathrm{LDH}-\mathrm{CO}_{3}$, being different (2.11 and 3, respectively), our last study found that for different $\mathrm{Mg} / \mathrm{Al}$ ratio $\mathrm{LDH}$ materials (from 2 to 6), similar behaviour for promoting ketonic decarboxylation was observed, suggesting the Mg:Fe ratio would have little effect and both samples can be compared for ketone production [10]. 
Several authors have pointed out that when reaching temperatures of around 300 to $450{ }^{\circ} \mathrm{C}$, ketone formation from carboxylic acids can be enhanced $[8,9,11,51]$, with a $100 \%$ yield reached at $300{ }^{\circ} \mathrm{C}$ [9]. However, when temperatures of $450{ }^{\circ} \mathrm{C}$ or above were used, others have stated that the pyrolytic decomposition of the carboxylic acid takes over from the ketonic decarboxylation reaction [12,52]. In this manner, the increase in ketone yield observed in Figure 5 at $300{ }^{\circ} \mathrm{C}$ was not surprising, evidencing that neither long reaction times nor more than catalytic amounts of catalyst are needed to promote a ketone yield up to $80 \%[7,10,12]$.

\section{Conclusions}

Ochre, an Fe-rich waste material produced from acid mine drainage treatment at Saltburn Gill, North East England, destined for landfill at cost to the tax payer, was converted to a $\mathrm{Mg} / \mathrm{Fe}$ layered double hydroxide (LDH) material, which was prepared with a $\mathrm{M}^{2+}: \mathrm{M}^{3+}$ ratio of 3, with potential use as an industrial catalyst. The catalytic activity of raw Saltburn ochre was examined for its ability to carry out ketonic decarboxylation; however, the performance of the latter was lower than the synthetic $\mathrm{Mg} / \mathrm{Fe} \mathrm{LDH}$ ( $\mathrm{LDH}-\mathrm{CO}_{3}$ (i.e., which used ochre as one of the main materials during its synthesis).

Impurities in the ochre as received could have affected the synthesis process, but a number of analyses confirmed successful formation of the desired LDH, though with some loss of control of Mg:Fe ratio. This evidences the potential to convert materials with costly disposal routes into industrially relevant commodities, necessary to develop the circular economy. In an additive sustainable chemical process, this catalyst was tested for heterogeneous base catalyst activity for the ketonic decarboxylation of lauric acid, a readily-obtained component of plant oils. Short periods of contact time at a temperature of $300{ }^{\circ} \mathrm{C}$ and low catalyst loadings proved to be sufficient to promote up to $80 \%$ of ketone formation. The presence of trace impurities in the waste material appeared to have little effect on the reactivity, relative to materials tested in prior studies prepared from high purity chemical feedstocks [10].

This study delivers a proof of concept that moves beyond using green chemistry principles for the chemical reaction process, $[53,54]$ to show how an efficient and green mixed metal catalyst can be obtained using ochre, a waste product from mine water treatment, to then undertake sustainable conversion of biomass-derived fatty acids to provide a valuable feedstock, ketones. This exemplifies a circular economy approach with reagents sourced from waste materials and combined with sustainable processes based on biomass conversion.

Supplementary Materials: The following are available online at http://www.mdpi.com/2075-163X/9/11/681/s1, Figure S1: The 12-tricosaone calibration curve. The ketone yield was estimated according to the following calibration curve, using a $0.1 \mathrm{M}$ solution of eicosane as the internal standard. Different concentrations of a 12-tricosanone solution were prepared diluting a $0.5 \mathrm{M}$ solution. Figure S2: PXRD pattern of calcined ochre at 800 ${ }^{\circ} \mathrm{C}$. The sample was calcined for $3 \mathrm{~h}$ in a muffle furnace. Figure S3: Chromatogram of the crude reaction product, with the small peak at 11.83 related to the 12-tricosanone and the sharp, high peak at 9.60 representing the internal standard eicosane. Table S1: Dewatering analysis of Saltburn ochre samples at a constant temperature of $60^{\circ} \mathrm{C}$. Table S2: All metals present in $15 \mathrm{mg}$ of $\mathrm{LDH}-\mathrm{CO}_{3}$ according to ICP-OES analysis. Table S3: Ketone yield using the synthetic salt derived $\mathrm{SLDH}-\mathrm{CO}_{3}$ at $300{ }^{\circ} \mathrm{C}$.

Author Contributions: Conceptualization, H.C.G., A.W. and D.D.P.-S.; methodology, H.C.G., A.W., E.F., M.P. and D.D.P.-S.; formal analysis, H.C.G., A.W. and D.D.P.-S.; investigation, D.D.P.-S., M.P., E.F.; writing—original draft preparation, H.C.G. and D.D.P.-S.; writing—review and editing, H.C.G. and D.D.P.-S.; supervision, H.C.G., A.W.; funding acquisition, H.C.G. and D.D.P.-S.

Funding: This research was funded by provision of a PhD studentship for D.D.P.-S. from CONACyT and APC were funded by UKRI via an award to Durham University. H.C.G. acknowledges funding from UKRI (Natural Environment Research Council, NERC) and Innovate UK via a Knowledge Transfer Partnership award, which led to this work.

Acknowledgments: We thank Chris Ottley and Emily Unsworth, from the Earth Sciences and Chemistry Department at Durham University, respectively, for assistance with ICP-OES for this study. We thank William Carswell, from the Chemistry Department, Durham University, for the TGA analysis of the samples. We thank Chris Satterley and Jon Aumonier at the Coal Authority, UK, for assistance in obtaining ochre. We also thank Aileen Congreve for her support with the use of the GC-FID and FTIR instruments.

Conflicts of Interest: The authors declare no conflicts of interest. 


\section{References}

1. De Bhowmick, G.; Sarmah, A.K.; Sen, R. Lignocellulosic biorefinery as a model for sustainable development of biofuels and value added products. Bioresour. Technol. 2018, 247, 1144-1154. [CrossRef] [PubMed]

2. Noraini, M.Y.; Ong, H.C.; Badrul, M.J.; Chong, W.T. A review on potential enzymatic reaction for biofuel production from algae. Renew. Sustain. Energy Rev. 2014, 39, 24-34. [CrossRef]

3. Shylesh, S.; Gokhale, A.A.; Ho, C.R.; Bell, A.T. Novel Strategies for the Production of Fuels, Lubricants, and Chemicals from Biomass. Acc. Chem. Res. 2017, 50, 2589-2597. [CrossRef] [PubMed]

4. Janampelli, S.; Darbha, S. Selective and reusable $\mathrm{Pt}-\mathrm{WO}_{\mathrm{x}} / \mathrm{Al}_{2} \mathrm{O}_{3}$ catalyst for deoxygenation of fatty acids and their esters to diesel-range hydrocarbons. Catal. Today 2017, 309, 219-226. [CrossRef]

5. Na, J.-G.; Han, J.K.; Oh, Y.-K.; Park, J.-H.; Jung, T.S.; Han, S.S.; Yoon, H.C.; Chung, S.H.; Kim, J.-N.; Ko, C.H. Decarboxylation of microalgal oil without hydrogen into hydrocarbon for the production of transportation fuel. Catal. Today 2012, 185, 313-317. [CrossRef]

6. Na, J.-G.; Yi, B.E.; Kim, J.N.; Yi, K.B.; Park, S.-Y.; Park, J.-H.; Kim, J.-N.; Ko, C.H. Hydrocarbon production from decarboxylation of fatty acid without hydrogen. Catal. Today 2010, 156, 44-48. [CrossRef]

7. Snell, R.W.; Shanks, B.H. Insights into the Ceria-Catalyzed Ketonization Reaction for Biofuels Applications. ACS Catal. 2013, 3, 783-789. [CrossRef]

8. Simakova, I.L.; Murzin, D.Y. Transformation of bio-derived acids into fuel-like alkanes via ketonic decarboxylation and hydrodeoxygenation: Design of multifunctional catalyst, kinetic and mechanistic aspects. J. Energy Chem. 2016, 25, 208-224. [CrossRef]

9. Corma, A.; Renz, M.; Schaverien, C. Coupling Fatty Acids by Ketonic Decarboxylation Using Solid Catalysts for the Direct Production of Diesel, Lubricants, and Chemicals. ChemSusChem 2008, 1, 739-741. [CrossRef]

10. Smith, B.; Li, L.; Perera-Solis, D.; Gildea, L.; Zholobenko, V.; Dyer, P.; Greenwell, H. Ketone Formation via Decarboxylation Reactions of Fatty Acids Using Solid Hydroxide/Oxide Catalysts. Inorganics 2018, 6, 121. [CrossRef]

11. Pham, T.N.; Sooknoi, T.; Crossley, S.P.; Resasco, D.E. Ketonization of Carboxylic Acids: Mechanisms, Catalysts, and Implications for Biomass Conversion. ACS Catal. 2013, 3, 2456-2473. [CrossRef]

12. Pulido, A.; Oliver-Tomas, B.; Renz, M.; Boronat, M.; Corma, A. Ketonic Decarboxylation Reaction Mechanism: A Combined Experimental and DFT Study. ChemSusChem 2013, 6, 141-151. [CrossRef] [PubMed]

13. Goh, K.-H.; Lim, T.-T.; Dong, Z. Application of layered double hydroxides for removal of oxyanions: A review. Water Res. 2008, 42, 1343-1368. [CrossRef] [PubMed]

14. Evans, D.G.; Slade, R.C.T. Structural Aspects of Layered Double Hydroxides. In Layered Double Hydroxides; Duan, X., Evans, D.G., Eds.; Springer: Berlin/Heidelberg, Germany, 2006.

15. Dobbie, K.E.; Heal, K.V.; Aumônier, J.; Smith, K.A.; Johnston, A.; Younger, P.L. Evaluation of iron ochre from mine drainage treatment for removal of phosphorus from wastewater. Chemosphere 2009, 75, 795-800. [CrossRef] [PubMed]

16. Heal, K.V.; Smith, K.; Younger, P.; McHaffie, H.; Batty, L. Removing phosphorus from sewage effluent and agricultural runoff using recovered ochre. In Phosphorus in Environmental Technology: Principles and Applications; Valsami-Jones, E., Ed.; IWA Publishing: London, UK, 2004; pp. 321-335.

17. Sapsford, D.; Santonastaso, M.; Thorn, P.; Kershaw, S. Conversion of coal mine drainage ochre to water treatment reagent: Production, characterisation and application for P and $\mathrm{Zn}$ removal. J. Environ. Manag. 2015, 160, 7-15. [CrossRef]

18. Littler, J.; Geroni, J.N.; Sapsford, D.J.; Coulton, R.; Griffiths, A.J. Mechanisms of phosphorus removal by cement-bound ochre pellets. Chemosphere 2013, 90, 1533-1538. [CrossRef]

19. Satterley, C.; The Coal Authority, Mansfield, United Kingdom. Personal communication, 2019.

20. Cavani, F.; Trifirò, F.; Vaccari, A. Hydrotalcite-type anionic clays: Preparation, properties and applications. Catal. Today 1991, 11, 173-301. [CrossRef]

21. Bumajdad, A.; Ali, S.; Mathew, A. Characterization of iron hydroxide/oxide nanoparticles prepared in microemulsions stabilized with cationic/non-ionic surfactant mixtures. J. Colloid Interface Sci. 2011, 355, 282-292. [CrossRef]

22. Song, S.; Jia, F.; Peng, C. Study on decomposition of goethite/siderite in thermal modification through XRD, SEM and TGA measurements. Surf. Rev. Lett. 2014, 21, 1450019. [CrossRef] 
23. Zhang, C.; Zhu, J.; Rui, X.; Chen, J.; Sim, D.; Shi, W.; Hng, H.H.; Lim, T.M.; Yan, Q. Synthesis of hexagonal-symmetry $\alpha$-iron oxyhydroxide crystals using reduced graphene oxide as a surfactant and their Li storage properties. CrystEngComm 2012, 14, 147-153. [CrossRef]

24. Shekoohi, K.; Hosseini, F.S.; Haghighi, A.H.; Sahrayian, A. Synthesis of some Mg/Co-Al type nano hydrotalcites and characterization. MethodsX 2017, 4, 86-94. [CrossRef] [PubMed]

25. Brito, A.; Borges, M.E.; Garín, M.; Hernández, A. Biodiesel Production from Waste Oil Using Mg-Al Layered Double Hydroxide Catalysts. Energy Fuels 2009, 23, 2952-2958. [CrossRef]

26. del Arco, M.; Malet, P.; Trujillano, R.; Rives, V. Synthesis and Characterization of Hydrotalcites Containing $\mathrm{Ni}(\mathrm{II})$ and $\mathrm{Fe}(\mathrm{III})$ and Their Calcination Products. Chem. Mater. 1999, 11, 624-633. [CrossRef]

27. Novillo, C.; Guaya, D.; Allen-Perkins Avendaño, A.; Armijos, C.; Cortina, J.L.; Cota, I. Evaluation of phosphate removal capacity of $\mathrm{Mg} / \mathrm{Al}$ layered double hydroxides from aqueous solutions. Fuel 2014, 138, 72-79. [CrossRef]

28. Das, J.; Patra, B.S.; Baliarsingh, N.; Parida, K.M. Adsorption of phosphate by layered double hydroxides in aqueous solutions. Appl. Clay Sci. 2006, 32, 252-260. [CrossRef]

29. Brian, G.; Erwan, A.; Christian, R.; Cedric, C. Tuning and Investigating the Structure of MII-FeIII Layered Double Hydroxides (MII = NiII, CoII and MgII) in Relation to their Composition: From Synthesis to Anionic Exchange Properties. Curr. Inorg. Chem. 2015, 5, 169-183. [CrossRef]

30. Duan, X.; Evans, D.G. Layered Double Hydroxides; Springer: Berlin/Heidelberg, Germany, 2006.

31. Xie, Y.; Yuan, X.; Wu, Z.; Zeng, G.; Jiang, L.; Peng, X.; Li, H. Adsorption behavior and mechanism of Mg/Fe layered double hydroxide with $\mathrm{Fe}_{3} \mathrm{O}_{4}$-carbon spheres on the removal of $\mathrm{Pb}$ (II) and $\mathrm{Cu}(\mathrm{II})$. J. Colloid Interface Sci. 2019, 536, 440-455. [CrossRef]

32. Ding, Y.; Liu, L.; Fang, Y.; Zhang, X.; Lyu, M.; Wang, S. The Adsorption of Dextranase onto Mg/Fe-Layered Double Hydroxide: Insight into the Immobilization. Nanomaterials 2018, 8, 173. [CrossRef]

33. Ahmed, I.M.; Gasser, M.S. Adsorption study of anionic reactive dye from aqueous solution to $\mathrm{Mg}-\mathrm{Fe}-\mathrm{CO} 3$ layered double hydroxide (LDH). Appl. Surf. Sci. 2012, 259, 650-656. [CrossRef]

34. Jia, X.; Li, D.; Evans, D.G.; Lin, Y. Optimization of the wash process and wash water recycling in the preparation of $\mathrm{MgZnAl}-\mathrm{CO}_{3}$ layered double hydroxides. Particuology 2010, 8, 231-233. [CrossRef]

35. Morterra, C.; Chiorlno, A.; Borello, E. An IR spectroscopic characterization of $\alpha$-FeOOH (goethite). Mater. Chem. Phys. 1984, 10, 119-138. [CrossRef]

36. Prasad, P.S.R.; Shiva Prasad, K.; Krishna Chaitanya, V.; Babu, E.V.S.S.K.; Sreedhar, B.; Ramana Murthy, S. In situ FTIR study on the dehydration of natural goethite. J. Asian Earth Sci. 2006, 27, 503-511. [CrossRef]

37. Xiao, W.; Jones, A.M.; Collins, R.N.; Bligh, M.W.; Waite, T.D. Use of fourier transform infrared spectroscopy to examine the Fe(II)-Catalyzed transformation of ferrihydrite. Talanta 2017, 175, 30-37. [CrossRef]

38. Richards, R. Surface and Nanomolecular Catalysis; CRC Press: Boca Raton, FL, USA, 2006.

39. Rouquerol, F.; Rouquerol, J.; Sing, K.S.W. Adsorption by Powders and Porous Solids: Principles, Methodology and Applications; Elsevier Science: Amsterdam, The Netherlands, 1999.

40. Das, J.; Sairam Patra, B.; Baliarsingh, N.; Parida, K.M. Calcined Mg-Fe-CO3 LDH as an adsorbent for the removal of selenite. J. Colloid Interface Sci. 2007, 316, 216-223. [CrossRef]

41. Cocheci, L.; Barvinschi, P.; Pode, R.; Popovici, E.; Seftel, E. Structural characterization of some Mg/Zn-Al type hydrotalcites prepared for chromate sorption from wastewater. Chem. Bull. Politeh. Univ. 2010, 55, 17.

42. Yang, K.; Yan, L.-G.; Yang, Y.-M.; Yu, S.-J.; Shan, R.-R.; Yu, H.-Q.; Zhu, B.-C.; Du, B. Adsorptive removal of phosphate by $\mathrm{Mg}-\mathrm{Al}$ and $\mathrm{Zn}-\mathrm{Al}$ layered double hydroxides: Kinetics, isotherms and mechanisms. Sep. Purif. Technol. 2014, 124, 36-42. [CrossRef]

43. Zhou, J.; Yang, S.; Yu, J.; Shu, Z. Novel hollow microspheres of hierarchical zinc-aluminum layered double hydroxides and their enhanced adsorption capacity for phosphate in water. J. Hazard. Mater. 2011, 192, 1114-1121. [CrossRef]

44. Pal, N.; Bhaumik, A. Mesoporous materials: Versatile supports in heterogeneous catalysis for liquid phase catalytic transformations. RSC Adv. 2015, 5, 24363-24391. [CrossRef]

45. Grégoire, B.; Ruby, C.; Carteret, C. Hydrolysis of mixed $\mathrm{Ni}^{2+}-\mathrm{Fe}^{3+}$ and $\mathrm{Mg}^{2+}-\mathrm{Fe}^{3+}$ solutions and mechanism of formation of layered double hydroxides. Dalton Trans. 2013, 42, 15687-15698. [CrossRef]

46. Masuda, T.; Kondo, Y.; Miwa, M.; Shimotori, T.; Mukai, S.R.; Hashimoto, K.; Takano, M.; Kawasaki, S.; Yoshida, S. Recovery of useful hydrocarbons from oil palm waste using $\mathrm{ZrO}_{2}$ supporting $\mathrm{FeOOH}$ catalyst. Chem. Eng. Sci. 2001, 56, 897-904. [CrossRef] 
47. Masuda, T.; Miwa, Y.; Hashimoto, K.; Ikeda, Y. Recovery of oil from waste poly(ethylene terephthalate) without producing any sublimate materials. Polym. Degrad. Stab. 1998, 61, 217-224. [CrossRef]

48. Oliver-Tomas, B.; Gonell, F.; Pulido, A.; Renz, M.; Boronat, M. Effect of the C $\alpha$ substitution on the ketonic decarboxylation of carboxylic acids over $\mathrm{m}-\mathrm{ZrO}_{2}$ : The role of entropy. Catal. Sci. Technol. 2016, 6, 5561-5566. [CrossRef]

49. Ignatchenko, A.V. Density Functional Theory Study of Carboxylic Acids Adsorption and Enolization on Monoclinic Zirconia Surfaces. J. Phys. Chem. C 2011, 115, 16012-16018. [CrossRef]

50. Takagi, K.; Shichi, T.; Usami, H.; Sawaki, Y. Controlled photocycloaddition of unsaturated carboxylates intercalated in hydrotalcite clay interlayers. J. Am. Chem. Soc. 1993, 115, 4339-4344. [CrossRef]

51. Deng, L.; Fu, Y.; Guo, Q.-X. Upgraded Acidic Components of Bio-oil through Catalytic Ketonic Condensation. Energy Fuels 2009, 23, 564-568. [CrossRef]

52. Maher, K.D.; Kirkwood, K.M.; Gray, M.R.; Bressler, D.C. Pyrolytic Decarboxylation and Cracking of Stearic Acid. Ind. Eng. Chem. Res. 2008, 47, 5328-5336. [CrossRef]

53. Torok, B.; Dransfield, T. Green Chemistry: An Inclusive Approach; Elsevier Science: Amsterdam, The Netherlands, 2017.

54. Anastas, P.; Eghbali, N. Green Chemistry: Principles and Practice. Chem. Soc. Rev. 2010, 39, $301-312$. [CrossRef]

(C) 2019 by the authors. Licensee MDPI, Basel, Switzerland. This article is an open access article distributed under the terms and conditions of the Creative Commons Attribution (CC BY) license (http://creativecommons.org/licenses/by/4.0/). 